\title{
The triglyceride paradox in the mortality of coronary artery disease
}

\author{
Tian-li Xia ${ }^{1 \dagger}$, Yi-ming Li ${ }^{2 \dagger}$, Fang-yang Huang ${ }^{1}$, Hua Chai', Bao-tao Huang ${ }^{1}$, Qiao Li ${ }^{1}$, Zhen-gang Zhao', \\ Yan-biao Liao' ${ }^{1}$ Zhi-liang Zuo ${ }^{1}$, Yong Peng ${ }^{1 *}$, Mao Chen $^{{ }^{*}}$ and De-jia Huang ${ }^{1}$
}

\begin{abstract}
Background: The role of triglyceride (TG) in secondary prevention of patients with coronary artery disease (CAD) was debated. In the present study, we assessed the association between admission TG levels and long-term mortality risk in CAD patients.

Methods: A retrospective analysis was conducted from a single registered database. 3061 consecutive patients with CAD confirmed by coronary angiography were enrolled and were grouped into 3 categories by the tertiles of admission serum TG levels. The primary end point in this study was all-cause mortality and the secondary end point was cardiovascular mortality.

Results: The mean follow-up time was $26.9 \pm 13.6$ months and death events occurred in 258 cases and cardiovascular death events occurred in 146 cases. Cumulative survival curves indicated that the risk of all-cause death decreased with increasing TG level (Tertile 1 vs. Tertile 2 vs. Tertile $3=10.3 \%$ vs. $8.6 \%$ vs. $6.3 \%$, log rank test for overall $p=0.001$ ). Cox regression analysis showed an independent correlation between TG level and risk of allcause mortality [hazard ratio (HR) $0.71,95 \%$ confidence interval (Cl) $0.58-0.86$ ] and cardiovascular mortality (HR 0.67, $95 \% \mathrm{Cl} 0.51-0.89)$ in total patients with CAD. Subgroup analysis found the similar results in patients with acute coronary syndrome and acute myocardial infarction.
\end{abstract}

Conclusions: This study found an inverse association between TG levels and mortality risk in CAD patients, which suggests that the "TG paradox" may exist in CAD patients.

Trial registration: ChiCTR, ChiCTR-OOC-17010433. Registered 17 February 2017 - Retrospectively registered.

Keywords: Prognosis, Hypertriglyceridemia, Paradox

\section{Introduction}

Hypertriglyceridemia (HTG) is considered a risk factor for atherosclerotic cardiovascular disease (ASCVD) [1]. Epidemiological studies showed that coronary artery disease (CAD) patients have higher triglyceride (TG) levels than the general population [2, 3]. Additionally, cohort studies showed that HTG can increase the risk of suffering from CAD [4-6]. However, the association between TG and ASCVD risk has been controversial. A series of studies suggested that there is no independent association between HTG and ASCVD risk after multifactor

\footnotetext{
* Correspondence: pengyongcd@126.com; hmaochen@vip.sina.com

†Tian-li Xia and Yi-ming Li contributed equally to this work.

${ }^{1}$ Department of Cardiology, West China Hospital, Sichuan University, 37

Guoxue Street, Chengdu 610041, People's Republic of China

Full list of author information is available at the end of the article
}

adjustment for cholesterol (TC), low-density lipoprotein cholesterol (LDL-C), and high-density lipoprotein cholesterol (HDL-C) [7]. The role of HTG was also debated in secondary prevention studies of patients who suffer from CAD. Some studies suggested that HTG increases the mortality risk in patients with CAD $[8,9]$; however, other studies suggested that there is no association between the two factors [10]. Several recent studies found an inverse association between admission TG level and mortality risk in stroke patients; these studies then proposed the concept of the "TG paradox" [11-14]. As one of ASCVD, CAD has the similar pathophysiological mechanism. Whether a similar TG paradox exists in CAD patients remains unclear.

In the present study, we assessed the association between admission TG levels and long-term mortality risk

(c) The Author(s). 2019 Open Access This article is distributed under the terms of the Creative Commons Attribution 4.0 International License (http://creativecommons.org/licenses/by/4.0/), which permits unrestricted use, distribution, and 
in $\mathrm{CAD}$ patients through analyzing a single-center cohort of 3061 consecutively enrolled patients with CAD.

\section{Methods \\ Study population}

The data source for this investigation was the West China Hospital CAD database. This single center database prospectively includes all the CAD or high risk patients undergoing angiography in West China Hospital affiliated to Sichuan University. For this analysis, we enrolled consecutive patients with CAD from January 2009 to September 2012 of the database. Patients with CAD were eligible for inclusion if they were restricted to participants with angiographic evidence of $\geq 50 \%$ stenosis in $\geq 1$ coronary vessels. The criteria of acute myocardial infarction (AMI) was diagnosed on the basis of the triad of chest pain, electrocardiogram changes, and elevated serum cardiac enzyme levels [15]. The criteria of stable angina pectoris was diagnosed on the basis of the symptom of exertional chest pain, angiographic evidence, and/or electrocardiogram changes, and normal serum cardiac enzyme levels. The criteria of unstable angina pectoris was diagnosed on the basis of criteria of AP and ischemic chest discomfort that increased or occurred at rest. The acute coronary syndrome (ACS) included AMI and unstable angina pectoris. The exclusion criteria included malignancies, pregnancy, end stage renal disease and severe liver or hematological diseases. These inclusion and exclusion criteria were met by 3365 continuously enrolled CAD patients. After excluding patients with loss of follow-up $(n=287)$ and missing data of TG ( $n=17), 3061$ patients were included in the data analysis. The study protocol was approved by ethics committee of West China Hospital, Sichuan University in accordance with the Declaration of Helsinki. All subjects provided written informed consent before enrolment.

\section{Baseline characteristics}

Demographic data, medical history, cardiovascular risk factor, vital signs at admission, medication at discharge, and final diagnosis were obtained from the patients' electronic medical records and reviewed by a trained study coordinator. Blood sample were collected at admission, and serum lipid including TG, liver and kidney function, blood glucose, etc. were analyzed in the department of Laboratory Medicine, West China hospital, accredited by the College of American Pathologists. TG level was measured by enzymatic colorimetric assay (Cobas 8000 C702 Chemistry autoanalyzer, Roche Diagnostics, Germany). Hypertension was defined as those with systolic blood pressure $(\mathrm{SBP}) \geq 140 \mathrm{mmHg}$ and/or diastolic blood pressure (DBP) $\geq 90 \mathrm{mmHg}$ and/or those receiving antihypertensive medications. Diabetes mellitus (DM) was diagnosed in patients who had previously undergone dietary treatment for diabetes, had received additional oral antidiabetic or insulin medication or had a current fasting blood glucose level of $\geq 7.0 \mathrm{mmol} / \mathrm{L}$ or random blood glucose level $\geq 11.1 \mathrm{mmol} / \mathrm{L}$. Patients received care according to the usual practice; treatment was not affected by participation in this study.

\section{Follow-up and end points}

The follow-up period ended on January 2013. Follow-up information was collected through contact with patients' physicians, patients or their family. All data were corroborated with the hospital records. The primary end point in this study was all-cause mortality and the secondary end point was cardiovascular death, as documented in the database. Death was considered cardiac when it was caused by acute MI, significant arrhythmias, or refractory heart failure. Sudden unexpected death occurring without another explanation was included as cardiovascular death.

\section{Statistical analyses}

We conducted the post-hoc analysis on a retrospective basis. Baseline demographics and clinical characteristics were compared among patients categorized by the tertiles of admission TG level in three groups. Continuous variables are expressed as the mean \pm standard deviation (SD), and categorical variables are reported as counts and percentages. Analysis of variance (ANOVA) and chi-squared tests were used to test for differences among groups for continuous and categorical variables, respectively. To determine the association between TG levels and all-cause mortality, Kaplan-Meier curves by tertiles of TG level were constructed and examined using the log-rank test for comparison. Cox proportional hazards models were used to evaluate the relationship of tertiles of TG level with all-cause and cardiovascular mortality, initially unadjusted and subsequently adjusting for several covariates: age, sex, medical history [pre-hypertension, pre-diabetes mellitus, pre-myocardial infarction, pre- percutaneous coronary intervention (pre-PCI), precardiac artery bypass graft (pre-CABG)], admission examination [systolic blood pressure, heart rate, body mass index (BMI) and Global Registry of Acute Coronary Events (GRACE) score)], admission lab test (blood glucose, serum creatinine, LDL-C and HDL-C), and severity of CAD (left main artery, three vessel diseases and number of stents) [16-18]. Cox proportional hazards regression models were also used to investigate the independent effect of TG level on all-cause and cardiovascular mortality in overall CAD patients and subgroups. Two-sided $p$ values of less than 0.05 indicated statistical significance. All analyses were performed with Stata MP (version 14.0). 


\section{Results}

A total of 3061 patients with CAD were included in the study. The average age was $64.4 \pm 10.7$ years, and men accounted for $79.4 \%$ of the patients. Serum TG levels were measured within $24 \mathrm{~h}$ after admission. The patients were divided into three groups according to the tertiles

Table 1 Baseline characteristics of the study population

\begin{tabular}{|c|c|c|c|c|c|}
\hline Characteristics & Total & Tertile 1 & Tertile 2 & Tertile 3 & $p$ value \\
\hline No. of patients & $n=3061$ & $n=1039$ & $n=1019$ & $n=1003$ & \\
\hline Age, yrs & $64.41(10.68)$ & $66.36(10.21)$ & $64.55(10.33)$ & $62.24(11.09)$ & $<0.001$ \\
\hline Gender, men, n (\%) & $2429(79.4)$ & $861(82.9)$ & $790(77.5)$ & $778(77.6)$ & 0.003 \\
\hline \multicolumn{6}{|l|}{ Medical history } \\
\hline Pre-hypertension, n (\%) & $1684(55.3)$ & $568(54.9)$ & $581(57.2)$ & $535(53.7)$ & 0.270 \\
\hline Pre-diabetes mellitus, n (\%) & $665(21.8)$ & $187(18.1)$ & $259(25.5)$ & $219(22.0)$ & $<0.001$ \\
\hline Pre-myocardial infarction, n (\%) & $830(27.1)$ & $303(29.2)$ & $283(27.8)$ & $244(24.3)$ & 0.041 \\
\hline Pre-PCl, n(\%) & $365(11.9)$ & $143(13.8)$ & $114(11.2)$ & $108(10.8)$ & 0.076 \\
\hline Pre-CABG, n(\%) & $34(1.1)$ & $9(0.9)$ & $13(1.3)$ & $12(1.2)$ & 0.642 \\
\hline \multicolumn{6}{|l|}{ At admission } \\
\hline Systolic blood pressure, mm Hg & $130.72(22.33)$ & $129.09(23.12)$ & $131.21(22.92)$ & $131.91(20.76)$ & 0.013 \\
\hline Diastolic blood pressure, $\mathrm{mm} \mathrm{Hg}$ & $76.49(12.57)$ & $75.31(12.76)$ & $76.58(12.38)$ & $77.62(12.46)$ & $<0.001$ \\
\hline Heart rate, beats/min & $74.34(22.98)$ & $74.88(29.59)$ & $74.30(22.92)$ & $73.82(13.11)$ & 0.584 \\
\hline Killip classification $\geq$ II, n (\%) & $345(11.3)$ & $136(13.1)$ & $121(11.9)$ & $88(8.8)$ & 0.007 \\
\hline GRACE score & $92.74(26.00)$ & $96.44(25.92)$ & $93.32(25.94)$ & $88.30(25.49)$ & $<0.001$ \\
\hline $\mathrm{BMI}$ & $24.40(6.75)$ & $23.55(3.34)$ & $24.72(10.34)$ & $24.94(4.23)$ & $<0.001$ \\
\hline \multicolumn{6}{|l|}{ Laboratory values } \\
\hline Serum creatinine, $\mu \mathrm{mol} / \mathrm{L}$ & $93.90(50.39)$ & $89.46(30.49)$ & $96.19(57.84)$ & $96.19(58.01)$ & 0.002 \\
\hline Blood glucose, mmol/L & $6.95(3.13)$ & $6.57(2.75)$ & $7.09(3.27)$ & $7.20(3.294)$ & $<0.001$ \\
\hline Total cholesterol, mmol/L & $4.07(1.12)$ & $3.69(0.94)$ & $4.02(1.00)$ & $4.52(1.25)$ & $<0.001$ \\
\hline $\mathrm{TG}, \mathrm{mmol} / \mathrm{L}$ & $1.75(1.13)$ & $0.91(0.18)$ & $1.48(0.19)$ & $2.89(1.32)$ & $<0.001$ \\
\hline $\mathrm{LDL}, \mathrm{mmol} / \mathrm{L}$ & $2.46(3.48)$ & $2.14(0.80)$ & $2.41(0.89)$ & $2.83(5.95)$ & $<0.001$ \\
\hline $\mathrm{HDL}, \mathrm{mmol} / \mathrm{L}$ & $1.15(0.35)$ & $1.26(0.34)$ & $1.15(0.36)$ & $1.03(0.31)$ & $<0.001$ \\
\hline Hemoglobin, g/L & $134.39(31.12)$ & $131.54(16.76)$ & $133.48(18.05)$ & $138.28(48.10)$ & $<0.001$ \\
\hline White blood cell, $n \times 10^{9} / \mathrm{L}$ & $7.48(4.94)$ & $7.13(3.00)$ & $7.69(7.06)$ & $7.64(3.78)$ & 0.017 \\
\hline \multicolumn{6}{|l|}{ Severity of CAD } \\
\hline Left main artery, n (\%) & $284(9.3)$ & $95(9.1)$ & $102(10.0)$ & $87(8.7)$ & 0.575 \\
\hline Three vessel diseases, n (\%) & $795(26.0)$ & $246(23.7)$ & $280(27.5)$ & $269(26.8)$ & 0.109 \\
\hline No. of stents & $1.22(1.22)$ & $1.17(1.19)$ & $1.26(1.21)$ & $1.24(1.27)$ & 0.195 \\
\hline \multicolumn{6}{|l|}{ Diagnose } \\
\hline$A C S, n(\%)$ & $2174(71.0)$ & $715(68.8)$ & $715(70.2)$ & $744(74.2)$ & 0.022 \\
\hline $\mathrm{AMI}, \mathrm{n}(\%)$ & $636(20.8)$ & $219(21.1)$ & $213(20.9)$ & $204(20.3)$ & 0.912 \\
\hline \multicolumn{6}{|l|}{ Discharge medications } \\
\hline Aspirin, n (\%) & $2812(91.9)$ & $951(91.5)$ & $938(92.1)$ & $923(92.0)$ & 0.963 \\
\hline Clopidogrel, n (\%) & $2735(89.3)$ & $905(87.1)$ & $917(90.0)$ & $913(91.0)$ & 0.088 \\
\hline Statins, n (\%) & $2754(90.0)$ & $934(89.9)$ & $921(90.4)$ & $899(89.6)$ & 0.958 \\
\hline ACE inhibitors or ARBs, $n(\%)$ & $1753(57.3)$ & $601(57.8)$ & $572(56.1)$ & $580(57.8)$ & 0.950 \\
\hline Beta-receptor blockers, n (\%) & $2028(66.3)$ & $634(61.0)$ & $671(65.8)$ & $723(72.1)$ & $<0.001$ \\
\hline
\end{tabular}

Data are expressed as means \pm SD or counts and percentages, as appropriate

Abbreviations: $B M I$ body mass index, $P C l$ percutaneous coronary intervention, $C A B G$ coronary artery bypass graft, $T G$ triglyceride, $L D L-C$ low-density lipoprotein cholesterol, $H D L-C$ high-density lipoprotein cholesterol, $C A D$ coronary artery disease, $A C E$ angiotensin-converting enzyme, $A R B s$ angiotensin-receptor blockers, GRACE score Global Registry of Acute Coronary Events score 
of TG levels. As shown by the baseline data distribution in Table 1, the clinical features showed differences among groups. Compared with lower TG level group, higher TG level group corresponded to higher TC and LDL-C levels, but lower HDL level, younger patient age, and better GRACE score.

The 3061 patients were followed up for an average duration of $26.9 \pm 13.6$ months. Total of death events occurred in 258 cases (mortality rate: 8.4\%) during the follow-up period, including 146 cases (cardiovascular mortality rate: $4.8 \%$ ) of cardiac death. As shown by the cumulative survival curves of groups by tertiles of TG level, the risk of all-cause mortality exhibited an overall rising trend as TG levels decreased (mortality rate, Tertile 1 vs. Tertile 2 vs. Tertile 3, $10.3 \%$ vs. $8.6 \%$ vs. $6.3 \%$, $\log$ rank test for overall $p=0.001$ ) (Fig. 1, panel a). The risk analysis of cardiac mortality obtained results similar trend to those mentioned above (cardiovascular mortality rate, Tertile 1 vs. Tertile 2 vs. Tertile 3, 5.9\% vs. 4.4\% vs. $4.0 \%, \log$ rank test for overall $p=0.067$ ) (Fig. 1, panel b). Even after multifactorial regression, TG level were still inversely correlated with risk of all-cause mortality and cardiovascular mortality (Table 2). Furthermore, similar trends were detected in patients with ACS (Fig. 1, panel $\mathrm{c}$ and panel d; and Table 2).

Cox regression analysis showed an independent correlation between TG level and risk of all-cause mortality and cardiovascular mortality in total patients with CAD. Subgroup analysis found the similar results in patients with ACS and AMI, except the cardiac mortality in patients with stable angina pectoris (Table 3 ).

\section{Discussions}

This study found an inverse association between TG levels and mortality risk in patients with CAD, which suggests that the "TG paradox" may exist in CAD patients.

The association between TG and ASCVD risk has not been less certain than that for LDL-C for a long time. Some studies suggested that TG has no association with
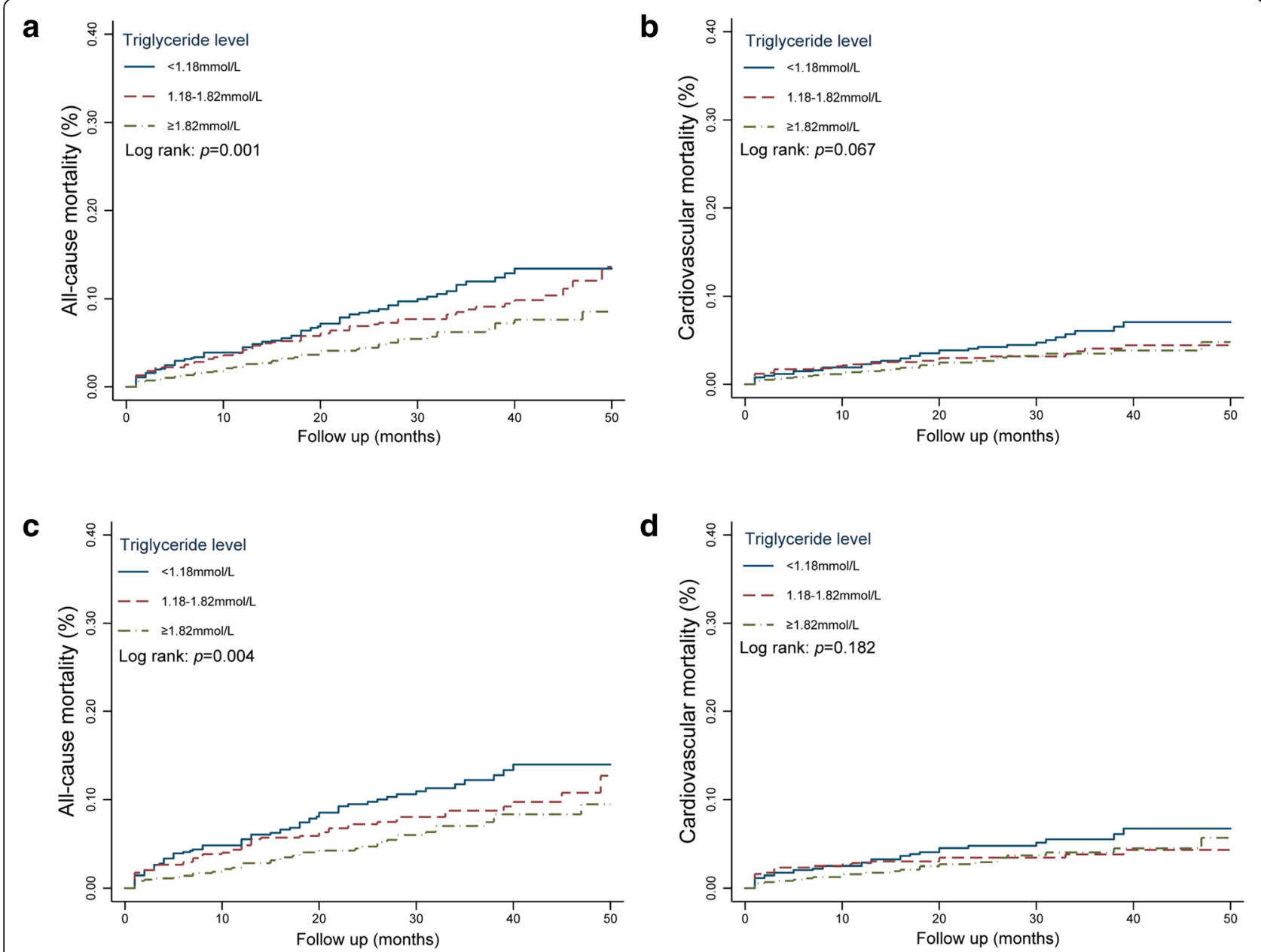

Fig. 1 Kaplan-Meier survival curves for all-cause mortality and cardiovascular mortality patients with coronary artery disease according to triglyceride levels. Panel $\mathbf{a}$ and Panel $\mathbf{b}$ in total 3061 patients with CAD; Panel $\mathbf{c}$ and Panel $\mathbf{d}$ in 2174 patients with ACS 
Table 2 Relationship of tertiles of triglyceride level to all-cause mortality in coronary artery disease

\begin{tabular}{|c|c|c|c|}
\hline & Tertile 1 & Tertile 2 & Tertile 3 \\
\hline \multicolumn{4}{|l|}{ Total patients } \\
\hline \multicolumn{4}{|c|}{ All-cause mortality, HR (95\% Cl) } \\
\hline Unadjusted & 1.00 & $0.80(0.59-1.09)$ & $0.53(0.38-0.75)$ \\
\hline Adjusted $^{a}$ & 1.00 & $0.75(0.53-1.05)$ & $0.49(0.32-0.74)$ \\
\hline \multicolumn{4}{|c|}{ Cardiovascular mortality, HR (95\% Cl) } \\
\hline Unadjusted & 1.00 & $0.69(0.44-1.09)$ & $0.60(0.37-0.95)$ \\
\hline Adjusted $^{\mathrm{a}}$ & 1.00 & $0.57(0.35-0.93)$ & $0.46(0.27-0.81)$ \\
\hline \multicolumn{4}{|l|}{ ACS patients } \\
\hline \multicolumn{4}{|c|}{ All-cause mortality, HR (95\% Cl) } \\
\hline Unadjusted & 1.00 & $0.72(0.51-1.04)$ & $0.53(0.36-1.04)$ \\
\hline Adjusted $^{a}$ & 1.00 & $0.66(0.45-0.97)$ & $0.53(0.34-0.82)$ \\
\hline \multicolumn{4}{|c|}{ Cardiovascular mortality, HR (95\% Cl) } \\
\hline Unadjusted & 1.00 & $0.68(0.41-1.15)$ & $0.65(0.38-1.10)$ \\
\hline Adjusted $^{\mathrm{a}}$ & 1.00 & $0.53(0.31-0.94)$ & $0.49(0.27-0.89)$ \\
\hline
\end{tabular}

Abbreviations: $H R$ hazard ratio, $A C S$ acute coronary syndrome, $\mathrm{Cl}$ confidence interval, LDL-C low-density lipoprotein cholesterol, HDL-C high-density lipoprotein cholesterol, CAD coronary artery disease, BMI body mass index, GRACE score Global Registry of Acute Coronary Events score.

${ }^{a}$ Risk factors adjustment included age, sex, medical history (pre-hypertension, prediabetes mellitus, pre-myocardial infarction, pre-PCl and pre-CABG), admission examination (systolic blood pressure, heart rate, BMI and GRACE score), admission lab test (blood glucose, serum creatinine, LDL-C and HDL-C), and severity of CAD (left main artery, three vessel diseases and number of stents)

Table 3 Relationship of triglyceride level with all-cause mortality in coronary artery disease and subgroups ${ }^{a}$

\begin{tabular}{|c|c|c|c|c|}
\hline & $\begin{array}{l}\text { All-Cause } \\
\text { Mortality }\end{array}$ & & $\begin{array}{l}\text { Cardiovascular } \\
\text { Mortality }\end{array}$ & \\
\hline & HR $(95 \% \mathrm{Cl})$ & $p$ & HR $(95 \% \mathrm{Cl})$ & $p$ \\
\hline \multicolumn{5}{|l|}{ Total patients } \\
\hline Unadjusted & $0.74(0.62-0.87)$ & $\begin{array}{l}< \\
0.001\end{array}$ & $0.77(0.60-0.97)$ & 0.028 \\
\hline Adjusted $^{b}$ & $0.71(0.58-0.86)$ & 0.001 & $0.67(0.51-0.89)$ & 0.006 \\
\hline \multicolumn{5}{|l|}{ ACS } \\
\hline Unadjusted & $0.71(0.60-0.88)$ & 0.001 & $0.80(0.61-1.04)$ & 0.096 \\
\hline Adjusted $^{b}$ & $0.72(0.58-0.90)$ & 0.003 & $0.69(0.51-0.94)$ & 0.018 \\
\hline \multicolumn{5}{|l|}{ AMI } \\
\hline Unadjusted & $0.63(0.46-0.87)$ & 0.005 & $0.53(0.33-0.85)$ & 0.008 \\
\hline Adjusted $^{b}$ & $0.71(0.50-1.01)$ & 0.057 & $0.51(0.30-0.86)$ & 0.012 \\
\hline \multicolumn{5}{|c|}{ Stable angina pectoris } \\
\hline Unadjusted & $0.74(0.52-1.06)$ & 0.099 & $0.62(0.36-1.06)$ & 0.086 \\
\hline Adjusted $^{b}$ & $0.61(0.39-0.95)$ & 0.028 & $0.59(0.24-1.16)$ & 0.127 \\
\hline
\end{tabular}

Abbreviations: $H R$ hazard ratio, $C l$ confidence interval, $A C S$ acute coronary syndrome, $A M I$ acute myocardial infarction, $L D L-C$ low-density lipoprotein cholesterol, $H D L-C$ high-density lipoprotein cholesterol, $C A D$ coronary artery disease, $B M I$ body mass index, GRACE score Global Registry of Acute Coronary Events score ${ }^{a}$ Triglyceride levels was grouped by the tertiles; ${ }^{\mathrm{b}}$ Risk factors adjustment included age, sex, medical history (pre-hypertension, pre-diabetes mellitus, pre-myocardial infarction, pre-PCI and pre-CABG), admission examination (systolic blood pressure, heart rate, BMI and GRACE score), admission lab test (blood glucose, serum creatinine, LDL-C and HDL-C), and severity of CAD (left main artery, three vessel diseases and number of stents)
CAD development or cardiovascular events [7, 19]. Some clinical trials did not find any direct improvement in primary outcomes in response to fibrate treatment [20]; meanwhile, no further decrease was found in cardiovascular events when comparing combination lipid therapy (statins and fibrates) with statin therapy alone [21]. Therefore, in the recommendation guidelines, HTG treatment is the second recommendation after LDL-C control [22]. A few recent studies found that low TG is associated with high mortality risk and poor prognosis in stroke; these studies then proposed the concept of a "TG paradox" $[11,14]$. Similar to stroke, CAD is an atherosclerotic disease, which prompts the following question: does the TG paradox also exist for cardiovascular disease? Two recent small-sample studies have provided some clues. Cheng et al. found that fasting the TG levels measured within $24 \mathrm{~h}$ of admission were inversely associated with hospital mortality and long-term prognosis such as target vessel revascularization and overall major adverse cardiac events, as indicated by an analysis of 247 ST elevation myocardial infarction (STEMI) patients undergoing primary PCI [23, 24]. Khawaja et al. observed a higher 3-year mortality risk in patients with lower fasting TG levels measured within $24 \mathrm{~h}$ of admission, as indicated by an analysis of 517 non-ST elevation myocardial infarction (NSTEMI) patients [24]. In the present study, our result is similar to the findings reported in the above two studies and it indicates that the "TG paradox" is present in the CAD cohort of our study.

Currently, the mechanism underlying the "TG paradox" is still unclear and may be related to the following factors. First, low TG levels may reflect the overall poor nutritional status of patients. Epidemiological and clinical controlled studies showed that TG levels are significantly influenced by the state of body weight and the distribution of body fat. Data from National Health and Nutrition Examination Surveys demonstrated a significant correlation between BMI and TG levels [25]. The Framingham Heart Study revealed that TG levels are strongly associated with abdominal subcutaneous fat and visceral fat distribution [26]. The "obesity paradox" is present in particular chronic wasting diseases, such as $\mathrm{CAD}$, heart failure, and chronic kidney disease, wherein BMI levels are inversely associated with mortality risk [27-29]. Thus, the TG level, which is significantly affected by BMI, may also present a similar paradox. Second, heparin use stimulated the release of lipoprotein lipase from endothelial cells, which can reduce the TG levels in blood circulation [30, 31]. Meanwhile, the greater sympathetic activity in acute phase of myocardial injury directly provokes the synthesis rate and activation of lipoprotein lipase, which breaks the TG from circulating state down to glycerol and fatty acids [31-34] It was 
previously reported that TG levels significantly decrease in ACS patients compared with stable angina pectoris patients within $24 \mathrm{~h}$ of onset and the low TG level were associated with the recurrent ischemia and the higher 30-days mortality in ACS patients [35-37]. Third, other basic research reported that HTG may have a potential protective role in vascular lesions. HTG can provide protective effects against fatty acid-induced lip toxicity [38]; additionally, blood lipid levels that are too low are detrimental to maintaining a stable state of cell membranes [39]. Finally, our study included a limited number of adjustment factors for the regression equation, and some unknown risk factors associated with TG might be overlooked, thus exaggerating the role of TG in the secondary prevention of CAD. Therefore, due to lack of large sample prospective study that is specifically designed to address the mechanism underlying this issue, but it is still inconclusive whether TG directly affects the prognosis of CAD patients or just plays a role as an indirect factor. These issues need to be further investigated.

This study has a few limitations. First, the study was a single-center observational study. Despite the multi-factor adjustment, it was difficult to completely avoid selection bias and the remaining confounding factors. Second, observational studies do not positively interfere with any diagnosis and treatment of patients; thus, a random TG measurement, other than the fasting TG, is used for emergency patients. In this study, the fasting TG level was collected from most elective coronary angiography patients (mainly with stable angina pectoris or unstable angina pectoris), while a random TG level was used for most emergency PCI patients (mainly with AMI). Therefore, the TG levels would be more susceptible to the effects of meal and thus increase in high-risk patients. However, in the current study, the percentages of AMI patients were similar in the various TG groups, suggesting that our results were not significantly affected by meals. The last, our analysis included only the measurement of laboratory and heart echocardiography completed within one week after admission of the patients to the hospital, which were not conducted during stable phase.

\section{Conclusion}

This study found an inverse association between TG levels and mortality risk in CAD patients, which suggests that the "TG paradox" may exist in CAD patients.

\section{Abbreviations}

ACS: Acute coronary syndrome; AMI: Acute myocardial infarction; ANOVA: Analysis of variance; ASCVD: Atherosclerotic cardiovascular disease; BMI: Body mass index; CAD: Coronary artery disease; DBP: Diastolic blood pressure; DM: Diabetes mellitus; ESRD: End stage renal disease; HDL-C: Highdensity lipoprotein cholesterol; HTG: Hypertriglyceridemia; LDL-C: Lowdensity lipoprotein cholesterol; MACE: Major adverse cardiac events; NSTEMI: Non-ST elevation myocardial infarction; SBP: Systolic blood pressure;
SD: Standard deviation; STEMI: ST elevation myocardial infarction; TC: Cholesterol; TG: Triglyceride

Acknowledgements

Not applicable.

\section{Funding}

This study was funded by the National Natural Science Foundation of China (grant number: 81400267 and 81370219 , Beijing, China) and the National High-tech Research and Development Program of China [2012AA02A510, Beijing, China].

\section{Availability of data and materials}

The data that support the findings of this study are available from the corresponding author upon reasonable request.

\section{Authors' contributions}

TLX, MC, DJH and YP participated in study conception and design. FYH, HC, and BTH performed the acquisition of data. TLX, YML, LYB, YWXO and QL participated in analysis and interpretation of data. ZGZ, ZLZ and YP drafted the manuscript and YP, MC, and DJH helped in critical review of the manuscript. All authors read and approved the final manuscript.

\section{Ethics approval and consent to participate}

This study was conducted after the acquisition of written informed consent from the participating patients and upon the approval by the ethics committee of West China Hospital, Sichuan University.

\section{Consent for publication}

If the manuscript is accepted, we approve it for publication in Lipids in Health and Disease.

\section{Competing interests}

The authors declare that they have no competing interests.

\section{Publisher's Note}

Springer Nature remains neutral with regard to jurisdictional claims in published maps and institutional affiliations.

\section{Author details}

${ }^{1}$ Department of Cardiology, West China Hospital, Sichuan University, 37 Guoxue Street, Chengdu 610041, People's Republic of China. ${ }^{2}$ West China School of Medicine, Sichuan University, Chengdu, China.

Received: 30 October 2018 Accepted: 8 January 2019

Published online: 22 January 2019

\section{References}

1. Miller M, Stone NJ, Ballantyne C, Bittner V, Criqui MH, Ginsberg HN, Goldberg AC, Howard WJ, Jacobson MS, Kris-Etherton PM, et al. Triglycerides and cardiovascular disease: a scientific statement from the American Heart Association. Circulation. 2011;123:2292-333.

2. Brunner D, Altman S, Loebl K, Schwartz S, Levin S. Serum cholesterol and triglycerides in patients suffering from ischemic heart disease and in healthy subjects. Atherosclerosis. 1977;28:197-204.

3. Gotto AM, Gorry GA, Thompson JR, Cole JS, Trost R, Yeshurun D, Debakey ME. Relationship between plasma lipid concentrations and coronary-artery disease in 496 patients. Circulation. 1977;56:875-83.

4. Benfante RJ, Reed DM, Maclean CJ, Yano K. Risk-Factors in middle-age that predict early and late onset of coronary heart-disease. J Clin Epidemiol. 1989:42:95-104.

5. Sarwar N, Danesh J, Eiriksdottir G, Sigurdsson G, Wareham N, Bingham S, Boekholdt SM, Khaw KT, Gudnason V. Triglycerides and the risk of coronary heart disease - 10158 incident cases among 262525 participants in 29 Western prospective studies. Circulation. 2007;115:450-8.

6. Hokanson JE, Austin MA. Plasma triglyceride level is a risk factor for cardiovascular disease independent of high-density lipoprotein cholesterol level : a meta-analysis of population-based prospective studies. J Cardiovasc Risk. 1996;3:213-9. 
7. Emerging Risk Factors C, Di Angelantonio E, Sarwar N, Perry P, Kaptoge S, Ray KK, Thompson A, Wood AM, Lewington S, Sattar N, et al. Major lipids, apolipoproteins, and risk of vascular disease. JAMA. 2009;302:1993-2000.

8. Klempfner R. Elevated triglyceride level is independently associated with increased all-cause mortality in patients with established coronary heart disease: twenty-two-year follow-up of the Bezafibrate infarction prevention study and registry (vol 9, pg 100, 2016). Circ Cardiovasc Qual Outcomes. 2016:9:613.

9. Kasai T, Miyauchi K, Yanagisawa N, Kajimoto K, Kubota N, Ogita M, Tsuboi S, Amano A, Daida H. Mortality risk of triglyceride levels in patients with coronary artery disease. Heart. 2013;99:22-9.

10. Stauffer ME, Weisenfluh L, Morrison A. Association between triglycerides and cardiovascular events in primary populations: a meta-regression analysis and synthesis of evidence. Vasc Health Risk Manag. 2013;9:671-80.

11. Dziedzic T, Slowik A, Gryz EA, Szczudlik A. Lower serum triglyceride level is associated with increased stroke severity. Stroke. 2004;35:E151-2.

12. Jain $M$, Jain $A$, Yerragondu $N$, Brown $R D$, Rabinstein A, Jahromi BS, Vaidyanathan L, Blyth B, Stead LG. The triglyceride paradox in stroke survivors: a prospective study. Neurosci J. 2013;2013:870608.

13. Ryu WS, Lee SH, Kim CK, Kim BJ, Yoon BW. Effects of low serum triglyceride on stroke mortality: a prospective follow-up study. Atherosclerosis. 2010;212:299-304.

14. Li W, Liu M, Wu B, Liu H, Wang LC, Tan S. Serum lipid levels and 3-month prognosis in Chinese patients with acute stroke. Adv Ther. 2008;25:329-41.

15. Alpert JS, Thygesen K, Antman E, Bassand JP. Myocardial infarction redefined--a consensus document of the joint European Society of Cardiology/American College of Cardiology Committee for the redefinition of myocardial infarction. J Am Coll Cardiol. 2000;36:959-69.

16. Tang EW, Wong C, Herbison P. Global registry of acute coronary events (GRACE) hospital discharge risk score accurately predicts long-term mortality post acute coronary syndrome. Am Heart J. 2007;153:29-35.

17. Eagle KA, Lim MJ, Dabbous OH, Pieper KS, Goldberg RJ, De Werf FV, Goodman SG, Granger CB, Steg PG, Gore JM. A validated prediction model for all forms of acute coronary syndrome: estimating the risk of 6-month postdischarge death in an international registry. JAMA. 2004;291:2727-33.

18. Elbarouni B, Goodman SG, Yan RT, Welsh RC, Kornder JM, Deyoung JP, Wong GC, Rose B, Grondin F, Gallo R. Validation of the global registry of acute coronary event (GRACE) risk score for in-hospital mortality in patients with acute coronary syndrome in Canada. Am Heart J. 2009;158:392-9.

19. Wilson PW, Anderson KM, Castelli WP. Twelve-year incidence of coronary heart disease in middle-aged adults during the era of hypertensive therapy: the Framingham offspring study. Am J Med. 1991;90:11-6.

20. Bezafibrate Infarction Prevention s. Secondary prevention by raising HDL cholesterol and reducing triglycerides in patients with coronary artery disease. Circulation. 2000;102:21-7.

21. Group AS, Ginsberg HN, Elam MB, Lovato LC, Crouse JR 3rd, Leiter LA, Linz $P$, Friedewald WT, Buse JB, Gerstein $\mathrm{HC}$, et al. Effects of combination lipid therapy in type 2 diabetes mellitus. N Engl J Med. 2010;362:1563-74.

22. National Cholesterol Education Program Expert Panel on Detection E, Treatment of High Blood Cholesterol in A. Third Report of the National Cholesterol Education Program (NCEP) Expert Panel on Detection, Evaluation, and Treatment of High Blood Cholesterol in Adults (Adult Treatment Panel III) final report. Circulation. 2002;106:3143-421.

23. Cheng YT, Liu TJ, Lai HC, Lee WL, Ho HY, Su CS, Liu CN, Wang KY. Lower serum triglyceride level is a risk factor for in-hospital and late major adverse events in patients with ST-segment elevation myocardial infarction treated with primary percutaneous coronary intervention- a cohort study. BMC Cardiovasc Disord. 2014;14:143-43.

24. Khawaja OA, Hatahet H, Cavalcante J, Khanal S, Al-Mallah MH. Low admission triglyceride and mortality in acute coronary syndrome patients. Cardiol J. 2011;18:297-303.

25. Ford ES, Li CY, Pearson WS, Mokdad AH. Hypertriglyceridemia and its pharmacologic treatment among US adults. Arch Intern Med. 2009;169:572-8.

26. Fox CS, Massaro JM, Hoffmann U, Pou KM, Maurovich-Horvat P, Liu CY, Vasan RS, Murabito JM, Meigs JB, Cupples LA, et al. Abdominal visceral and subcutaneous adipose tissue compartments - association with metabolic risk factors in the Framingham heart study. Circulation. 2007;116:39-48.

27. Hastie CE, Padmanabhan S, Slack R, Pell ACH, Oldroyd KG, Flapan AD, Jennings KP, Irving J, Eteiba H, Dominiczak AF, Pell JP. Obesity paradox in a cohort of 4880 consecutive patients undergoing percutaneous coronary intervention. Eur Heart J. 2010;31:222-6.
28. Curtis. The obesity paradox: body mass index and outcomes in patients with heart failure (vol 165, pg 55, 2005). Arch Intern Med. 2008;168:567.

29. Kalantar-Zadeh K, Streja E, Kovesdy CP, Oreopoulos A, Noori N, Jing J, Nissenson AR, Krishnan M, Kopple JD, Mehrotra R, Anker SD. The obesity paradox and mortality associated with surrogates of body size and muscle mass in patients receiving hemodialysis. Mayo Clin Proc. 2010;85:991-1001.

30. Tornvall P, Olivecrona G, Karpe F, Hamsten A, Olivecrona T. Lipoproteinlipase mass and activity in plasma and their increase after heparin are separate parameters with different relations to plasma-lipoproteins. Arterioscler Thromb Vasc Biol. 1995;15:1086-93.

31. Klingenspor M, Ebbinghaus C, Hulshorst G, Stohr S, Spiegelhalter F, Haas K, Heldmaier G. Multiple regulatory steps are involved in the control of lipoprotein lipase activity in brown adipose tissue. J Lipid Res. 1996;37:1685-95.

32. Festuccia WT, Blanchard P-G, Richard D, Deshaies Y. Basal adrenergic tone is required for maximal stimulation of rat brown adipose tissue UCP1 expression by chronic PPAR- $\gamma$ activation. American Journal of PhysiologyRegulatory, Integrative and Comparative Physiology. 2010;299: R159-R167.

33. Pecquery R, Leneveu MC, Giudicelli Y. In vivo desensitization of the beta, but not the alpha 2-adrenoreceptor-coupled-adenylate cyclase system in hamster white adipocytes after administration of epinephrine. Endocrinology. 1984;114:1576-83.

34. Lefebvre P, Luyckx A, Bacq ZM. Effects of denervation on the metabolism and the response to glucagon of white adipose tissue of rats. Horm Metab Res. 1973;5:245-50.

35. Henkin Y, Crystal E, Goldberg Y, Friger M, Lorber J, Zuili I, Shany S. Usefulness of lipoprotein changes during acute coronary syndromes for predicting postdischarge lipoprotein levels. Am J Cardiol. 2002:89:7-11.

36. Correia LC, Magalhaes LP, Braga JC, Rocha MS, Lima JC, Passos LC, D'Oliveira A, Pericles Esteves J, Sposito AC. Decrease of plasma triglycerides during the acute phase of unstable angina or non-ST elevation myocardial infarction is a marker of recurrent ischemia. Atherosclerosis. 2004;177:71-6.

37. Cheng KH, Chu CS, Lin TH, Lee KT, Sheu SH, Lai WT. Lipid paradox in acute myocardial infarction-the association with 30-day in-hospital mortality. Crit Care Med. 2015:43:1255-64.

38. Listenberger LL, Han X, Lewis SE, Cases S, Farese RV Jr, Ory DS, Schaffer JE. Triglyceride accumulation protects against fatty acid-induced lipotoxicity. Proc Natl Acad Sci U S A. 2003;100:3077-82.

39. Eryurek FG, Surmen E, Oner P, Altug T, Oz H. Gamma-glutamyl transpeptidase and acetylcholinesterase activities in brain capillaries of cholesterol-fed rabbits. Res Commun Chem Pathol Pharmacol. 1990;69:245-8.

\section{Ready to submit your research? Choose BMC and benefit from:}

- fast, convenient online submission

- thorough peer review by experienced researchers in your field

- rapid publication on acceptance

- support for research data, including large and complex data types

- gold Open Access which fosters wider collaboration and increased citations

- maximum visibility for your research: over $100 \mathrm{M}$ website views per year

At BMC, research is always in progress.

Learn more biomedcentral.com/submissions 